\title{
Uptake of Killed Yersinia enterocolitica by Pseudopodia of M Cells in the Peyers' Patches of the Murine Small Intestines
}

\author{
Ken-ichi KANEKO, Kohkichi UEHARA ${ }^{1)}$ and Masuo OGAWA \\ Department of Veterinary Medicine ${ }^{1}$ Scleroprotein and Leather Research Institute, Faculty of Agriculture, Tokyo University of \\ Agriculture and Technology, 3-5-8 Saiwai-cho, Fuchu-shi, Tokyo 183-8509, Japan \\ (Received 8 January 1999/Accepted 1 June 1999)
}

ABSTRACT. To understand the mechanisms of uptake of killed bacteria of Yersinia enterocolitica serovar O3 into the epithelium of Peyer's patches, the killed bacteria were perorally inoculated into mice and observation was carried out by scanning and transmission electron microscopy. Microfold (M) cells formed a specific pseudopodium-like structure and the bacteria were observed on the surface and the interior of the pseudopodium-like structure $8 \mathrm{hr}$ after oral administration of killed bacteria of serovar O3.—KEY wORDS: M cell, pseudopodium, Yersinia enterocolitica.

J. Vet. Med. Sci. 61(10): 1175-1177, 1999

It has been shown that microfold (M) cells in the epithelium of the Peyer's patches dome region are involved in the initial stage of the invasion of enteropathogens [2, 8, 11]. An association of $M$ cells with the intestinal invasion of Yersinia known as an agent of human gastroenteritis is known [1, 3-5]. The mechanism of the invasion of these pathogens into the $\mathrm{M}$ cells, however, is still obscure.

The killed bacteria are generally considered as substances digested to small molecules in the gastrointestines by the enzymes of the host. Although Kaneko et al. [7] suggested the presence of killed bacteria of Yersinia enterocolitica serovar O3 in the epithelium of the Peyer's patches dome region by using optical microscopy, it is not known yet whether or not the $\mathrm{M}$ cells are associated with these results. To find the role of $\mathrm{M}$ cells in the uptake of killed bacteria, the present study was intended to clarify the association of $M$ cells with the uptake of killed bacteria and the formation of a pseudopodium-like structure in the Peyer's patches by using scanning and transmission electron microscopes.

The mice used were ten 4-week-old specific-pathogenfree ICR mice purchased from the Shizuoka Agric. Coop. Assoc. Lab. Anim., Shizuoka, Japan. A strain of serovar O3 isolated from a brown rat harboring 45-magadaltons virulence plasmid was used. Biochemical characters of this strain (SD1416-11) were described in a previous report [6]. The bacteria grown on Trypticase soy agar (BBL) for $48 \mathrm{hr}$ at $25^{\circ} \mathrm{C}$ were resuspended in physiological saline, washed three times, and suspended in physiological saline.

Formaldehyde was added to a final concentration of $1 \%$ to the suspension of the live bacteria, and the suspension was kept standing at room temperature for over one day. The formalin-killed bacteria were centrifuged to remove formaldehyde and the precipitate was resuspended in physiological saline to a final concentration of $500 \mathrm{mg} / \mathrm{ml}$. A $100-\mathrm{mg}\left(10^{10}\right.$ cells $)$ portion of the killed bacteria per mouse were given orally through a gastric feeding tube.

The Peyer's patches of the small intestines were obtained from the mice anesthetized with ethyl ether 8 and $24 \mathrm{hr}$ after the oral administration, since Kaneko et al. [7] reported the uptake of the killed bacteria of the serovar O3 began 4 to $8 \mathrm{hr}$ after oral administration. The small intestines were excised from four mice under anesthesia with ethyl ether 8 and $24 \mathrm{hr}$ after oral inoculation and from two control mice. The small intestines excised were rinsed in PBS. The Peyer's patches were collected from the small intestines and soaked in $2.5 \%$ glutaraldehyde $10 \mathrm{~min}$ after excision of the small intestines. After overnight fixation with glutaraldehyde, the specimens were fixed with osmic acid according to the routine method. The specimens were washed, dehydrated through a graded series of ethanol and transferred to isoamyl acetate for scanning electron microscopy. After critical-point drying, the specimens were coated with gold with an ion sputtering apparatus and observed under a scanning electron microscope (JEOL $\mathrm{T} 330 \mathrm{~A})$ at $15 \mathrm{kV}$.

For transmission electron microscopy, the specimens dehydrated were embedded in Epon. Ultrathin (70 to 80 $\mathrm{nm}$ ) sections were stained with uranyl acetate and lead citrate and examined under a JEOL 100C transmission electron microscope.

Figure 1 shows M cells in the epithelium of the Peyer's patches 8 and $24 \mathrm{hr}$ after oral administration of serovar O3 killed bacteria. M cells formed a specific structure like a pseudopodium and the bacteria were observed on the surface $8 \mathrm{hr}$ after the administration. Some bacteria were in close contact with the surface and some were embedded in the specific structure of $\mathrm{M}$ cells. Although the bacteria were not observed, $M$ cells were still forming the specific pseudopodium-like structure $24 \mathrm{hr}$ after the administration. On the other hand, the pseudopodium-like structure was not observed in the control mice not given the killed serovar O3 bacteria.

Figure 2 shows M cells in the epithelium of the Peyer's patches $8 \mathrm{hr}$ after the oral administration. The killed bacteria were still in the lumen of the small intestines. M cells formed the same specific structure as that observed by scanning electron microscopy. The killed bacteria were observed on the surface and the interior of the pseudopodium.

The bacteria were taken up only by the pseudopodium of the $\mathrm{M}$ cell. The killed bacteria were not seen in microvilli of the $\mathrm{M}$ cell. A thinner pseudopodium was observed in $\mathrm{M}$ 

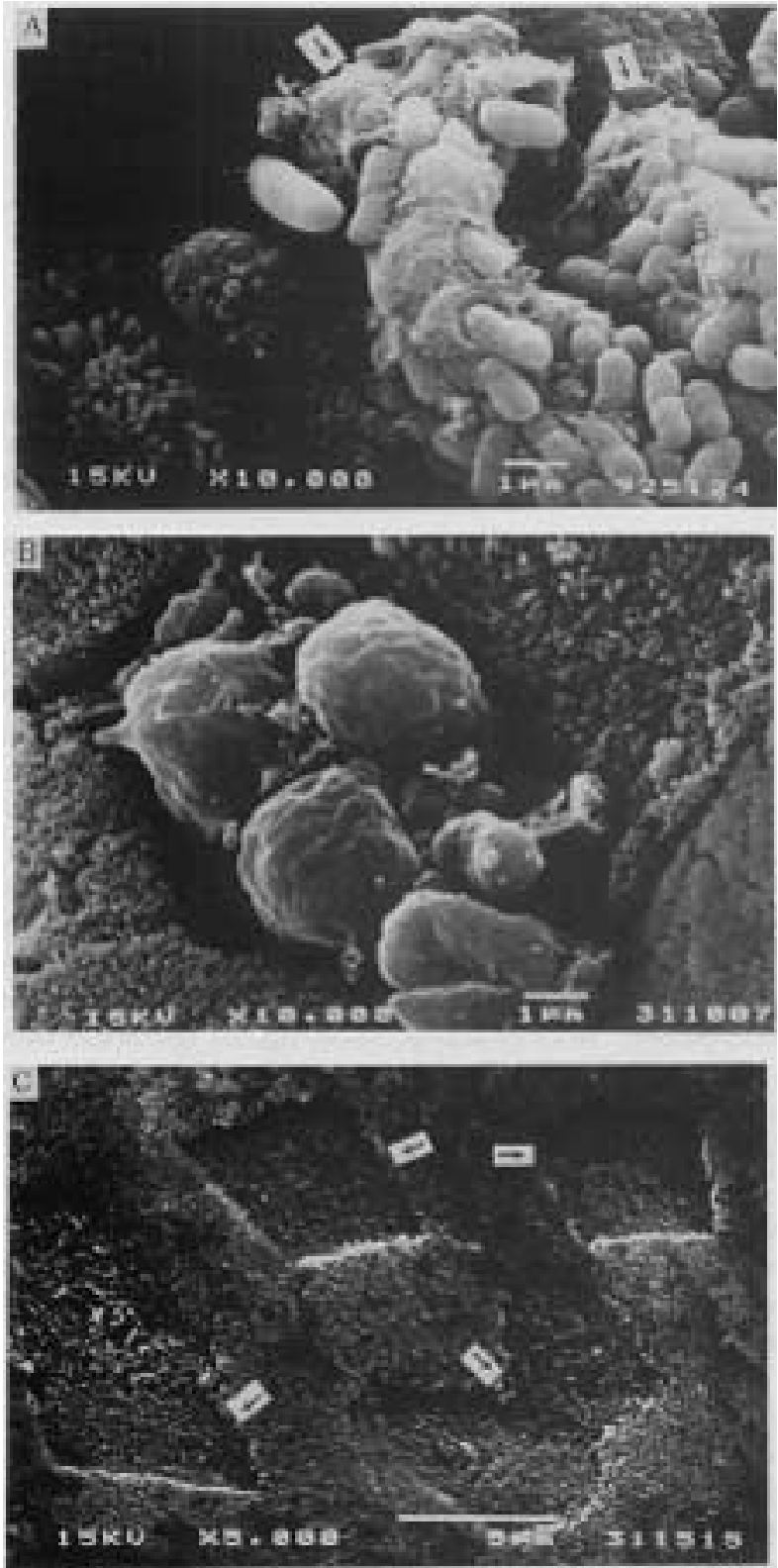

Fig. 1. Formation of a specific pseudopodium-like structure by M cells in the dome epithelium after oral administration of killed bacteria of serovar O3. Scanning electron microscopy observed that the killed bacteria are on the surface of the epithelium and the specific structure was formed from $\mathrm{M}$ cells $8 \mathrm{hr}$ after the oral administration (Fig. 1A). The arrows point pseudopodia of M cells intaking the killed bacteria. Some of the killed bacteria are on the surface of the pseudopodium-like structure of M cells, and some are embedded in the pseudopodium-like structure (original magnification $\times 10,000$ ). Figure 1B shows the surface of M cells $24 \mathrm{hr}$ after the oral administration. The $\mathrm{M}$ cells are still forming the pseudopodium-like structure, although no bacteria are seen on the surface of $\mathrm{M}$ cells (original magnification $\times 10,000$ ). Figure $1 \mathrm{C}$ shows the epithelium of the dome in the Peyer's patches of control mice. Four arrows point four $M$ cells. They are surfaced with microvilli and without forming pseudopodia (original magnification $\times 5,000$ ). No bacteria are observed. cells containing full the bacteria in its cytoplasm. Some of the killed bacteria were surrounded by the unit membrane of the pseudopodium of $\mathrm{M}$ cells. Certain $\mathrm{M}$ cells taking the killed bacteria formed a thick pseudopodium which was in contact with the bacteria not only in the lumen but also in the cytoplasm of polymorphonuclear neutrophils.

Although the enzyme and noninvasive Vibrio cholerae are known to be taken by $M$ cells $[8,9]$, the present study first demonstrated that killed bacteria 1 to $2 \mu \mathrm{m}$ in length were transported from the intestinal lumen to the epithelium by active intake of M cells' pseudopodia in the Peyer's patches. These facts suggest the probability that the same sized substances without digestion were taken by the $\mathrm{M}$ cells from the intestinal lumen. Although the bacteria were not observed in the lumen of the small intestines of the control mice not given the killed bacteria, it seems necessary to demonstrate the presence of the killed bacteria of serovar $\mathrm{O} 3$ in $\mathrm{M}$ cells by an immunological method.

Although there are some reports on the involvement of $M$ cells in the initial step of the infection with enteric pathogens [1-5], the formation of the pseudopodium as big as that demostrated in the present study is not known. Therefore, the pseudopodia may have been developed specifically for uptake of the killed bacteria. Oral administration of killed $Y$. enterocolitica into mice is known to induce immunoglobulin A secretion in 20 days [10]. The present study demonstrated that uptake of killed bacteria by the pseudopodia of $\mathrm{M}$ cells occurred as early as $8 \mathrm{hr}$ after oral administration. The uptake by the pseudopodia might be the first step of inducing the intestinal immune response of the host. Future investigations are necessary to find whether all species or only specific species of killed bacteria are taken by $\mathrm{M}$ cells. It was shown that the killed bacteria in the pseudopodia were transported to the cytoplasm of either the same $\mathrm{M}$ cell or neutrophils. After they had been transported to the cytoplasm of $\mathrm{M}$ cells or neutrophils, the fate of the killed bacteria was not demonstrated in the present study, therefore it may be of interest to know the subsequent reaction in future investigation.

The short irregular microvilli are seen in the rabbit $\mathrm{M}$ cells taking live $V$. cholerae [9], Shigella flexineri [11], or $Y$. enterocolitica $[1,5]$. They are seen also in the mouse $M$ cells taking enzyme [8] and virus [2]. In the present study, the microvilli of $\mathrm{M}$ cells could not function of uptaking the killed bacteria, because the bacteria were observed in neither the $M$ cell cytoplasm surfaced with microvilli nor the microvilli themselves. Although microvilli of the intestinal epithelial cells are considered to broaden absorbing the region of epithelial cells, future studies are warranted to find whether or not the microvilli of the $\mathrm{M}$ cells function as extra membrane when $\mathrm{M}$ cells form the pseudopodia.

\section{REFERENCES}

1. Autenrieth, I. B. and Firsching, R. 1996. J. Med. Microbiol. 44: 285-294.

2. Bass, D. M., Trier, J.S., Dambrauskas, R. and Wolf, J.L. 1988. Lab. Invest. 55: 226-235. 

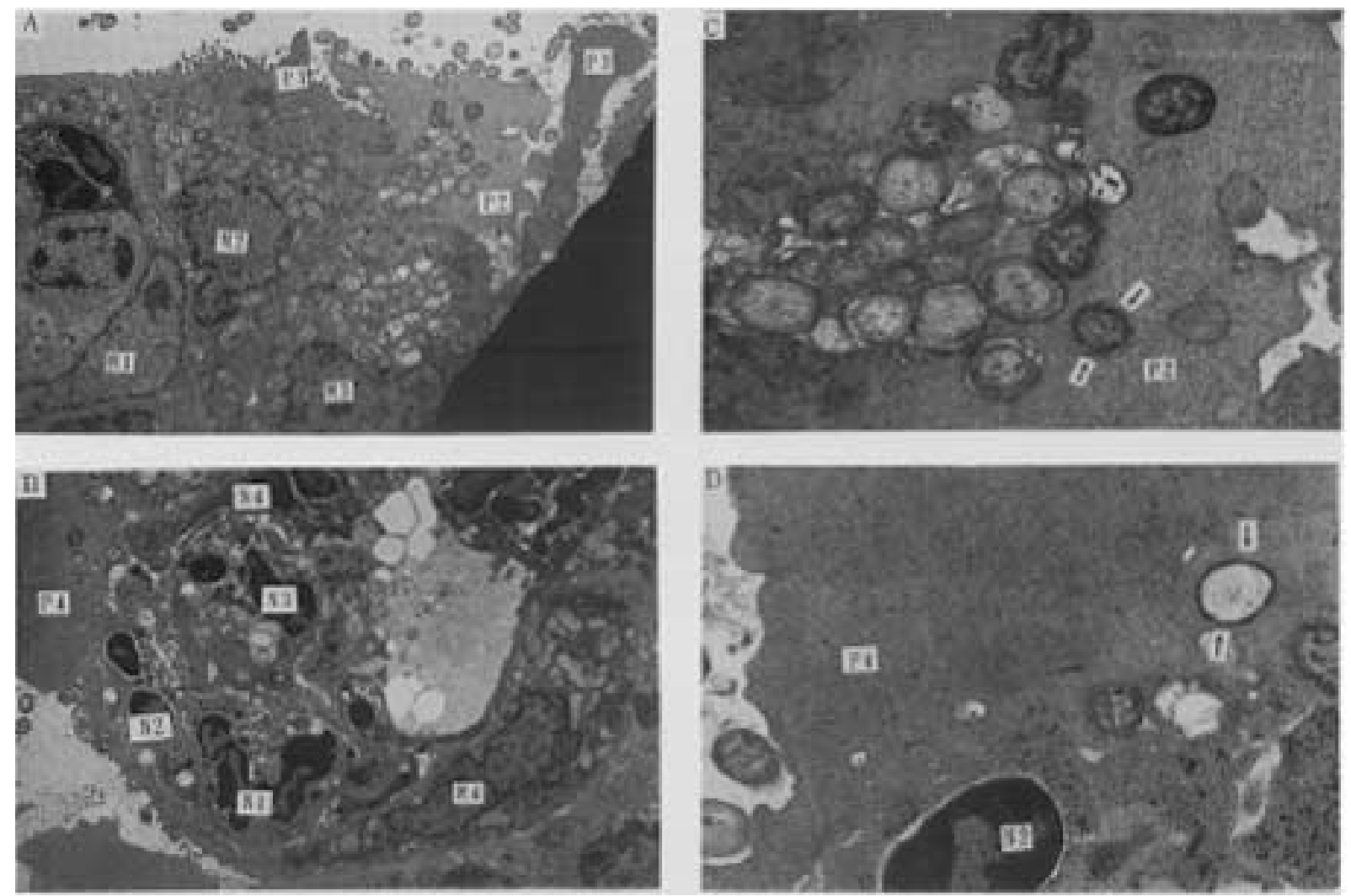

Fig. 2. Uptake of killed bacteria by pseudopodia of $\mathrm{M}$ cells $8 \mathrm{hr}$ after the oral administration of killed bacteria of serovar O3. Four M cells and four pseudopodia are shown by transmission electron microscopy. The bacteria are short rods 1 to $2 \mu \mathrm{m}$ in length. The M1 cell has taken up no bacteria due to the lack of pseudopodium in Fig. 2A (original magnification $\times 2,000$ ). The M2 cell having two pseudopodia (P1 and P2) has taken up the bacteria by its bigger and thick pseudopodium (P2). More than 30 bacteria are observed on the surface or within the thick pseudopodium in Fig. 2A. A small immature pseudopodium (P1) formed in M2 cell has not started to take the bacteria. In the cytoplasm surfaced with microvilli of the $\mathrm{M}$ cell, however, the bacteria are not present. M3 cell contains more than 20 bacteria in its cytoplasm with a thin pseudopodium (P3) taking only two bacteria in Fig. 2A. M4 cell has a thick pseudopodium (P4) having taken more than eight bacteria in Fig. 2B (original magnification $\times 2,000$ ). M4 cell has transported the bacteria to the cytoplasm of three of four adjoining neutrophils having polymorphonucleus through the pseudopodium (P4). Figure 2B shows that none of bacteria are in the cytoplasm of neutrophil (N1), two are between the cytoplasm of a neutrophil (N2) and P4, one between the neutrophil (N4) and P4, more than ten in the cytoplasm of neutrophil (N3) which is not in contact with P4 in this section. One bacterium is observed between the neutrophil and P4 (Fig. 2D). Figures 2C and 2D are higher magnification of two pseudopodia (P2 and $\mathrm{P} 4$ ) to show the killed bacteria surrounded by the membrane of the pseudopodium of $\mathrm{M}$ cell (original magnification $\times 5,000$ ). The arrows indicate the unit membrane of the interior of the pseudopodium surrounding the outer membrane of the killed bacterium.

3. Clark, M. A., Hirst, B. H. and Jepson, M. A. 1998. Infect. Immun. 66: 1237-1243.

4. Grutzkau, A., Hanski, C., Hahn, H. and Riecken, E. O. 1990. Gut 31: 1011-1015.

5. Heesemann, J., Gaede, K. and Autenreith, I. B. 1993. Acta Pathol.Microbiol. Immunol. Scand. 101: 417-429.

6. Kaneko, K. and Hashimoto, N. 1982. Int. J. Syst. Bacteriol. 32: 275-287.

7. Kaneko, K., Uehara, K. and Ogawa, M. 1991. Contrib.
Microbiol. Immunol. 12: 156-158.

8. Owen, R.L. 1977. Gastroenterology 72: 440-451.

9. Owen, R.L., Pierce N.F., Apple R. T. and Cray, W.C. 1986. J. Infect. Dis. 153: 1108-1119.

10. Shimono, K., Kaneko, K., Hayashidani, H. and Ogawa, M. 1989. Jpn. J. Vet. Sci. 51: 273-277.

11. Wassef, J.S., Keren, D.F. and Mailloux, J. L. 1989. Infect. Immun. 57: 858-863. 